\title{
Influência da Variabilidade Climática sobre a Erosividade em Belém (PA)
}

\author{
Carlos Eduardo Aguiar de Souza Costa $^{1}$ iD, Claudio José Cavalcante Blanco ${ }^{2}$ in \\ ${ }^{1}$ Programa de Pós-Graduação em Engenharia Civil, Instituto de Tecnologia, \\ Universidade Federal do Pará, Belém, PA, Brasil. \\ ${ }^{2}$ Faculdade de Engenharia Sanitária e Ambiental, Instituto de Tecnologia, \\ Universidade Federal do Pará, Belém, PA, Brasil.
}

Recebido em 6 de Dezembro de 2016 - Aceito em 5 de Janeiro de 2018

\begin{abstract}
Resumo
A Universal Soil Loss Equation (USLE) é um modelo no qual a perda de solo é o produto de vários índices, entre eles o de erosividade da chuva $(R)$. Este fator identifica quando ocorre o maior risco de erosão hídrica. Objetivou-se analisar a influência do ENOS (El Niño Oscilação Sul) e Dipolo do Atlântico sobre o fator $R$ em Belém (PA). As erosividades de 1986 a 2015 foram classificadas quanto à intensidade. Os eventos ENOS também foram classificados para se avaliar uma possível influência de sua amplitude. O Índice de Oscilação do Niño (ION) foi usado para verificar a ocorrência do ENOS. Para analisar o Dipolo do Atlântico, foram utilizados os índices TNA (Tropical Northern Atlantic) e TSA (Tropical Southern Atlantic), pois este fenômeno interfere diretamente no principal sistema atmosférico da região, a Zona de Convergência Intertropical (ZCIT). Análises de correlação de Pearson e regressão linear foram determinadas entre o $R$ e os índices climáticos. Assim, foram observadas menores erosividades em anos de El Niño intenso, obtendo-se maiores coeficientes de correlação. Coincidência de La Niña intenso com Dipolo Negativo também representaram maiores coeficientes de correlação, significando o aumento da erosividade. Houve fraca correlação da erosividade durante Dipolo Positivo.
\end{abstract}

Palavras-chave: erosão hídrica, El Niño, La Niña, Dipolo do Atlântico.

\section{Influence of Climate Variability on Erosivity in Belém (PA)}

\begin{abstract}
The Universal Soil Loss Equation (USLE) is a model in which soil loss is the product of several indices, including rainfall erosivity $(\mathrm{R})$. This factor identifies when the greatest risk of water erosion occurs. The objective of this study was to analyze the influence of ENOS (El Niño Southern Oscillation) and Atlantic Dipole on the R factor in Belém (PA). Erosivities from 1986 to 2015 were classified according to intensity. ENSO events were also classified to evaluate a possible influence of their amplitude. The Niño Oscillation Index (ION) was used to verify the occurrence of ENSO. In order to analyze the Atlantic Dipole, the TNA (Tropical Northern Atlantic) and TSA (Tropical Southern Atlantic) indices were used, because this phenomenon directly interferes in the region's main atmospheric system, the Intertropical Convergence Zone (ZCIT). Pearson correlation analysis and linear regression were determined between R and climatic indexes. Thus, lower erosivities were observed in years of intense El Niño, obtaining higher correlation coefficients. Coincidence of intense La Niña with Negative Dipole also represented higher correlation coefficients, meaning the increase of erosivity. There was a weak correlation of erosivity during Positive Dipole.
\end{abstract}

Keywords: water erosion, El Niño, La Niña, Atlantic Dipole.

\section{Introdução}

Dentre os fatores da Universal Soil Loss Equation (USLE), Lee e Heo (2011) afirmam que o fator de erosividade da chuva $(\mathrm{R})$ tem sido usado como o principal parâmetro na avaliação da erosão hídrica do solo, produção de sedimentos e monitoramento da qualidade da água. A motivação para o uso deste fator ocorre devido a sua maior susceptibilidade a mudanças climáticas. O fator de erosividade é obtido através da média dos valores do índice de erosividade $\left(E I_{30}\right)$, que por sua vez, é calculado pelo produ-

Autor de correspondência: Claudio José Cavalcante Blanco, blanco@ufpa.br. 
to entre a energia cinética específica por lâmina de chuva e a intensidade máxima de chuva ocorrida em 30 minutos. Segundo Machado et al. (2013), este índice já vem sendo utilizado em várias localidades no Brasil, sendo recomendado por ser o índice oficial da USLE. Existem outros parâmetros, mas no Brasil o $E I_{30}$ é o que apresenta melhor correlação com perda de solo (Waltrick et al., 2015).

As variabilidades climáticas também podem ser causadas por fenômenos, tais como: El Niño Oscilação Sul (ENOS), que são decorrentes das variações de fluxos de calor e de vapor d'água da superfície do Oceano Pacífico Equatorial para a atmosfera (Collins et al., 2010). Segundo Nur'utami e Hidayat (2016), essas variações influenciam diretamente nas Células de Walker, que são células de circulação atmosférica Leste-Oeste ao longo do cinturão equatorial, respondendo as diferenças na temperatura do oceano. Ainda segundo os autores, as flutuações da circulação Walker podem levar a condições climáticas extremas em diferentes partes do mundo.

O El Niño é caracterizado pelo enfraquecimento dos ventos alísios, o que permite que as águas fiquem mais aquecidas do que o normal, podendo influenciar também no posicionamento de um dos principais sistemas atmosféricos existentes no Oceano Atlântico, a Zona de Convergência Intertropical (ZCIT), que tende a ficar posicionada mais ao norte (Ferreira e Mello, 2005). Em fases de La Niña, ocorre o processo contrário, ou seja, os ventos alísios são mais intensos, favorecendo o ressurgimento das águas mais frias à superfície e, consequentemente, diminuindo a evaporação (Chen et al., 2016). Ferreira e Mello (2005) afirmam ainda que nessa situação, geralmente, a ZCIT fica posicionada mais ao sul.

Segundo Okumura et al. (2001), outro fenômeno climático que influencia ainda mais no posicionamento da ZCIT é o Dipolo do Atlântico (Gradiente Inter-Hemisférico ou Gradiente Meridional). Trata-se de um o fenômeno oceano/atmosférico identificado como uma mudança anômala na temperatura da superfície da água do mar no Oceano Atlântico Tropical. Por exemplo, um aquecimento do Atlântico Tropical Norte relativo ao Sul, leva a uma mudança para o norte da ZCIT, causando movimentos descendentes e transportando ar frio e seco dos altos níveis da atmosfera sobre a região setentrional, central e sertão do Nordeste inibindo a formação de nuvens e diminuindo a precipitação (Dipolo Positivo) (Nóbrega et al., 2016). Por sua vez, um aumento da Temperatura da Superfície do Mar (TSM) do Atlântico Equatorial Sul em relação ao Norte se caracteriza como Dipolo Negativo, fazendo com que a ZCIT se posicione mais ao sul, aumentando os movimentos ascendentes, intensificando a formação de nuvens e aumentando os índices pluviométricos (Menezes et al., 2008).

A erosão hídrica e a consequente produção de sedimentos têm sido uma preocupação constante em todas as situações relativas à gestão do solo e da água. A importância de estudos sobre a erosividade da chuva vem ga- nhando cada vez mais destaque, principalmente porque além das perdas de solo, as chuvas também causam grandes danos em infraestruturas e obras de engenharia hidráulica (Santos et al., 2010). Um dos maiores problemas ocorre quando os sedimentos são arrastados, o que provoca o assoreamento na bacia hidrográfica, diminuindo a seção de vazão dos canais de macrodrenagem e aumentando os riscos de enchentes. Dimensionamentos mais eficientes de obras hidráulicas (urbanas ou rurais) podem ser realizados quando são considerados aspectos de risco e frequência da chuva (Evangelista et al., 2012).

São poucos os trabalhos que abordam a erosividade da chuva na Amazônia. Ainda mais escassos são os estudos que avaliam a influência de fenômenos climáticos sobre este fator, sendo que esta é a área com os maiores totais de precipitação do país. Assim, objetivou-se analisar a influência do ENOS e Dipolo do Atlântico sobre a erosividade das chuvas em Belém (PA) no período de 1986 a 2015 .

\section{Material e Métodos}

\subsection{Região de estudo}

Belém está situada na zona equatorial, às margens da Baía do Guajará e Rio Guamá (Fig. 1), com área territorial de $1.059,458 \mathrm{~km} 2$ e 1.432.844 habitantes (IBGE, 2016). A região caracteriza-se por apresentar temperaturas de $26,4^{\circ}$ em média, ar instável e umidade do ar média de $84 \%$, favorecendo a formação de nuvens convectivas (Bastos et al., 2002). A precipitação pluvial média anual é de 3.000 a $4.000 \mathrm{~mm}$ e a cidade está localizada na zona climática Af (classificação de Köppen) (Alvares et al., 2013).

\subsection{Dados utilizados}

\subsection{1. Índice de Erosividade (EI 30$)$}

Para otimizar o tempo de pesquisa, alguns dos valores de erosividade utilizados neste estudo foram os determinados por Melo et al. (2014) e atualizados por Barbosa et al. (2015). Os autores adotaram critérios para individualização das chuvas erosivas baseados naqueles propostos por Wischmeier e Smith (1965). De posse de pluviogramas digitalizados dos anos de 2001 a 2011, eles consideraram chuvas erosivas aquelas que apresentaram altura total precipitada igual ou superior a $10 \mathrm{~mm}$. Para totais precipitados inferiores a $10 \mathrm{~mm}$, as chuvas foram consideradas erosivas apenas quando a lâmina precipitada em 15 minutos foi de $6 \mathrm{~mm}$ ou mais. Assim, foram obtidos os valores de $E I_{30}$ mensais, somando-se os índices de todas as chuvas erosivas por mês, gerando-se a erosividade mensal (Tabela 1).

Irvem et al. (2007) buscaram determinar o índice de erosividade em estações que não possuíssem registros horários de chuva. Correlacionando a erosão anual com o índice de Fournier modificado $(R c)$, os autores concluíram que este coeficiente permite uma aproximação satisfatória para o cálculo do fator de erosividade da chuva, sendo 


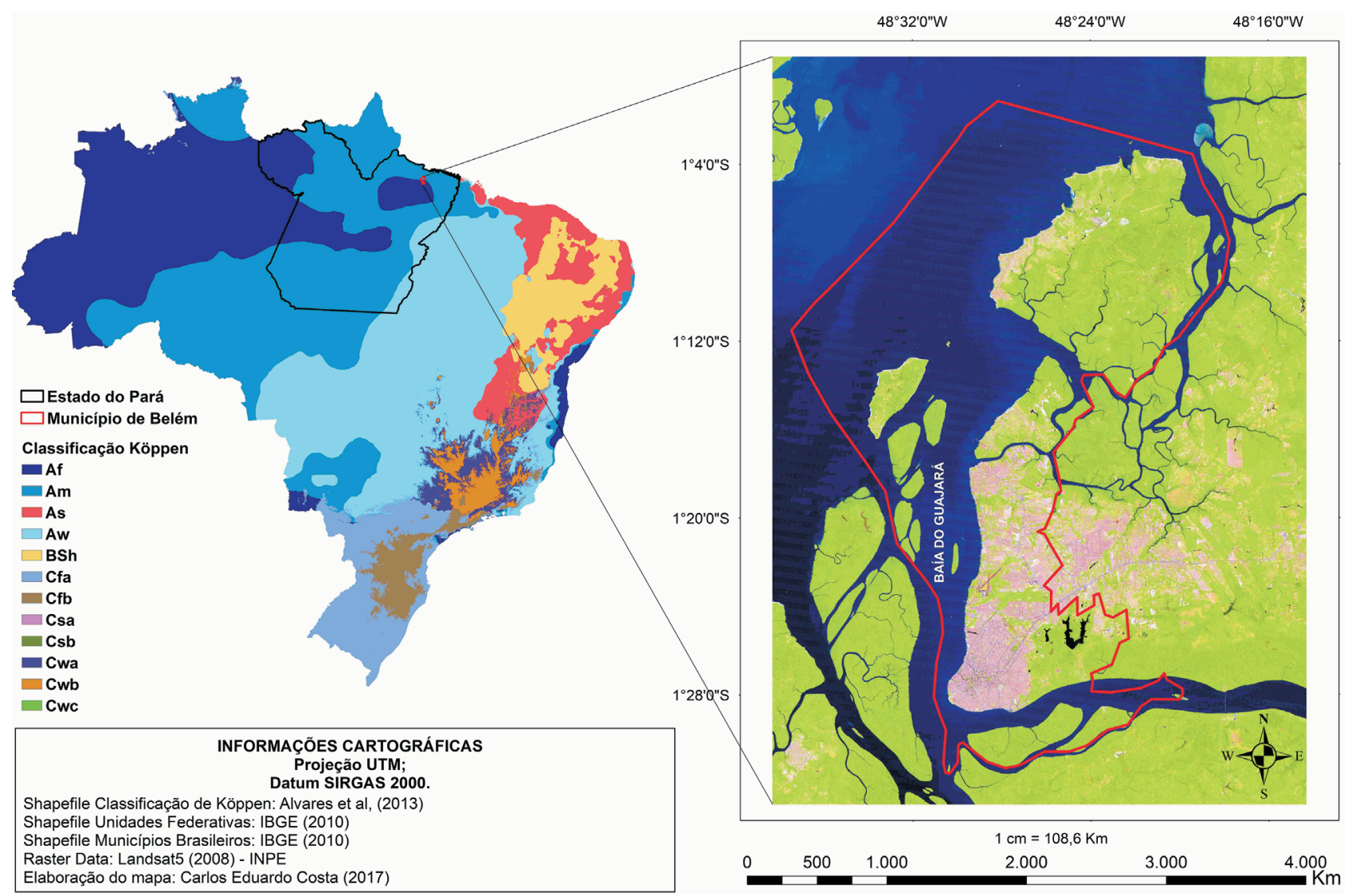

Figura 1 - Região de estudo.

Tabela 1 - Erosividade mensal obtida de 2001 a $2011\left(\mathrm{MJ} \mathrm{mm} \mathrm{ha}^{-1} \mathrm{~h}^{-1} \mathrm{mês}^{-1}\right)$.

\begin{tabular}{lcccccccccccc}
\hline Ano/Mês & Jan & Fev & Mar & Abr & Mai & Jun & Jul & Ago & Set & Out & Nov & Dez \\
\hline 2001 & 1900,2 & 1044,2 & 1520,7 & 1672,4 & 998,7 & 1076,0 & 2671,0 & 41,7 & 479,5 & 1792,3 & 176,0 & 2392,4 \\
2002 & 931,2 & 452,5 & 1883,5 & 3704,1 & 225,6 & 790,4 & 442,0 & 183,2 & 915,6 & 120,1 & 210,2 & 1238,6 \\
2003 & 539,0 & 1331,2 & 1558,7 & 418,4 & 625,6 & 445,6 & 256,0 & 497,3 & 1050,4 & 570,4 & 557,6 & 1352,5 \\
2004 & 1601,6 & 1344,3 & 1958,7 & 1683,7 & 16 & 860,1 & 462,8 & 145,7 & 182,7 & 692,0 & 196,6 & 1986,1 \\
2005 & 893,9 & 1710,2 & 2650,8 & 3425,9 & 969 & 2405,3 & 2740,1 & 558,1 & 173,7 & 1431,1 & 116,4 & 1620,6 \\
2006 & 2062,5 & 545,7 & 3407,0 & 2581,8 & 1056,0 & 114,9 & 262,3 & 1887,9 & 1117,3 & 522,0 & 1283,0 & 3105,5 \\
2007 & 1278,4 & 1683,7 & 1470,9 & 1176,1 & 724,2 & 1003,0 & 29,3 & 764,7 & 18,6 & 572,2 & 431,9 & 4894,3 \\
2008 & 1384,0 & 1252,7 & 4793,7 & 1628,6 & 990,5 & 1429,3 & 191,2 & 962,2 & 628,3 & 265,5 & 551,3 & 585,9 \\
2009 & 1376,5 & 1069,8 & 3351,3 & 1395,2 & 3398,3 & 1007,2 & 288,6 & 464,5 & 999,6 & 1181,3 & 0,0 & 1122,9 \\
2010 & 2670,9 & 1635,2 & 1062,8 & 1645,9 & 1903,9 & 444,5 & 878,9 & 2001,6 & 188,3 & 954,3 & 145,6 & 543,7 \\
2011 & 1840,9 & 1003,0 & 2336,7 & 2907,7 & 3669,8 & 687,1 & 316,1 & 948,4 & 94,2 & 147,2 & 928,0 & 397,7 \\
\hline
\end{tabular}

Fonte: Barbosa et al. (2015), Melo et al. (2014).

utilizado também para estimar valores em regiões com climas semelhantes. Diante disto, também foram estabelecidas relações do tipo linear e potencial entre o $E I_{30}$ de todos os anos e o Rc (obtido através do quadrado da precipitação média mensal, dividido pela precipitação média anual). A relação que obteve melhor coeficiente de regressão foi a linear, $R^{2}=0,9657$.

\subsection{2. Índices climáticos}

De acordo com Paula et al. (2010), existem diversos critérios para definir as fases e a intensidade do fenômeno ENOS. A metodologia mais difundida foi criada pela $\mathrm{Na}$ tional Oceanic and Atmospheric Administration (NOAA), na qual um episódio de El Niño ou La Niña é definido pelo 
Índice de Oscilação do Niño (ION) resultante da média móvel trimestral da TSM do Oceano Pacífico. Segundo Marcuzzo et al. (2013), o El Niño é caracterizado quando o índice é maior ou igual a $0,5^{\circ} \mathrm{C}$ e a La Niña quando o índice for menor ou igual a $-0,5^{\circ} \mathrm{C}$ por, no mínimo, cinco meses consecutivos. Diante disso, foram obtidos os dados mensais de ION no período de 1986 a 2015, totalizando 30 anos, os quais foram avaliados juntamente com os dados de erosividade mensais.

Para averiguar as situações anômalas que ocorrem no Atlântico Equatorial, a NOAA também realiza a medição de dois índices que compõem o Padrão do Dipolo do Atlântico, o TNA (Tropical Northern Atlantic) e o TSA (Tropical Southern Atlantic). De acordo com Sales (2014), para obter os índices dessa anomalia, a série semanal é linearmente interpolada com a série diária para calcular o ciclo climatológico sazonal com resolução diária. Em seguida, calcula-se a média mensal e para cada mês da série, obtém-se a anomalia subtraindo-se da média climatológica. Tanto a anomalia TNA, como a TSA, são calculadas pelo mesmo método.

\subsection{Metodologia}

\subsubsection{Cálculo e classificação da erosividade}

A equação de regressão linear (Fig. 2) foi utilizada para extrapolar os dados de erosividade de 1986 a 2000 e de 2012 a 2015, para se obterem 30 anos de dados, como é preconizado pela organização mundial de meteorologia para realizar uma análise climática eficiente.

Posteriormente, todos os resultados de erosividade (1986 a 2015) foram classificados conforme os valores

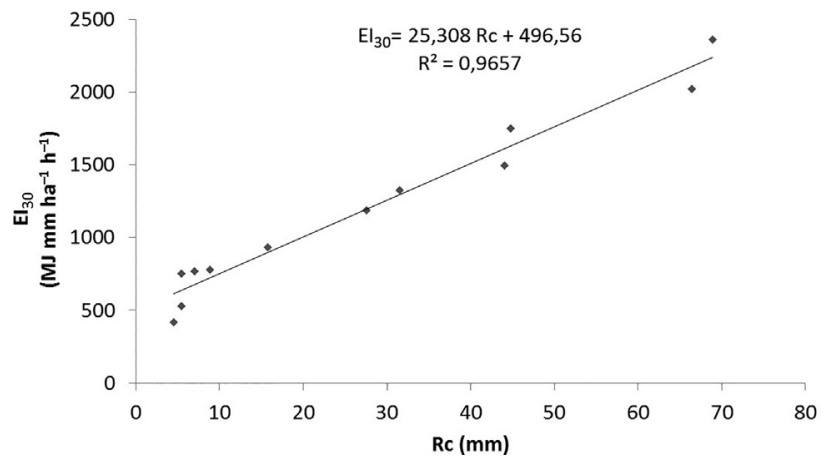

Figura 2 - Correlação Linear entre o $E I_{30}$ e o $R c$ da precipitação pluviométrica (2001 a 2011). Fonte: Barbosa et al. (2015). propostos por Batjes (1996), na Tabela 2, que se adequam aos valores de uma região com altos índices de erosividade (Febles et al., 2009).

\subsubsection{Classificação do evento ENOS}

Tomando como base o trabalho de Marcuzzo et al. (2013), os eventos ENOS foram classificados e analisados quanto a sua intensidade segundo critério apresentado pelo Golden Gate Weather Service (Tabela 3).

\subsubsection{Fases do Dipolo do Atlântico e cálculo do Gradiente Inter-Hemisférico (GIH)}

As fases do Dipolo do Atlântico foram definidas através dos gradientes inter-hemisféricos, calculados com base na diferença entre os índices (TNA-TSA) para o período de 1986 a 2015. O critério para determinação da fase do gradiente foi baseado no método de Souza et al. (2005), no qual o Dipolo Positivo/Negativo ocorre quando o GIH assume valores consecutivos maiores/iguais a $0,2{ }^{\circ} \mathrm{C}$ ou menores/iguais a $-0,2{ }^{\circ} \mathrm{C}$ em pelo menos 4 meses. $\mathrm{O}$ sinal positivo/negativo indica gradiente de TSM para norte/sul no Atlântico Tropical, influenciando no posicionamento da ZCIT e por sua vez nas precipitações pluviométricas (Reboita e Santos, 2015).

\subsubsection{Correlação de Pearson e regressão linear}

Foi realizada a análise de correlação de Pearson e de regressão linear entre os Índices de Erosividade $\left(E I_{30}\right)$ mensais e os Índices Oceânicos do Niño (ION) mensais dentro dos intervalos anuais. O objetivo foi verificar o grau de associação entre as duas variáveis, buscando identificar uma possível interferência no potencial erosivo das chuvas a partir de anomalias de TSM no Oceano Pacífico. Efetua-

Tabela 3 - Classificação da intensidade do fenômeno ENOS.

\begin{tabular}{lcc}
\hline Evento & Valor do ION $\left({ }^{\circ} \mathrm{C}\right)$ & Intensidade \\
\hline El Niño & $\geq 1,5$ & Forte \\
& 1 a 1,4 & Moderado \\
& 0,5 a 0,9 & Fraco \\
Neutralidade & $-0,4$ a 0,4 & Neutralidade \\
La Niña & $-0,5$ a $-0,9$ & Fraco \\
& -1 a $-1,4$ & Moderado \\
& $\leq-1,5$ & Forte \\
\hline
\end{tabular}

Fonte: Golden Gate Service (2016).

Tabela 2 - Classificação do índice médio de erosividade.

\begin{tabular}{lcc}
\hline Erosividade $\left(\mathrm{Mj} \mathrm{mm} \mathrm{ha}^{-1} \mathrm{~h}^{-1} \mathrm{mês}\right)$ & Erosividade $\left(\mathrm{Mj} \mathrm{mm} \mathrm{ha}{ }^{-1} \mathrm{~h}^{-1}\right.$ Ano $)$ & Classe de erosividade \\
\hline $\mathrm{R} \geq 1.250$ & $\mathrm{R} \geq 15.000$ & Alta \\
$800<\mathrm{R}<1.250$ & $9.600<\mathrm{R}<15.000$ & Média \\
$\mathrm{R} \leq 800$ & $\mathrm{R} \leq 9.600$ & Baixa \\
\hline
\end{tabular}

Fonte: Batjes (1996). 
ram-se os mesmos cálculos entre os Índices de erosividade mensais e os GIH dentro dos períodos anuais, buscando os períodos em que os potencias erosivos da chuva fossem mais sensíveis à influência do Dipolo do Atlântico, e consequentemente ao posicionamento da ZCIT.

A classificação utilizada para os níveis de correlação e regressão (Tabela 4) foi baseada no trabalho de Cavalcante (2003), no qual para uma correlação $(R)$ aceitável foram considerados todos os valores da classe Média $(0,60)$ ou acima. Já para o coeficiente de determinação $\left(R^{2}\right)$ valores aceitáveis estão incluídos na classe Forte $(0,36)$ ou acima.

A significância da correlação foi calculada e avaliada através do teste T de Student. Adotou-se um limite crítico para a significância $(\alpha)$ de 0,05 , no qual para esse valor de $\alpha$ (considerando o número de 12 amostras), o valor de intervalo para a hipótese não ser considerada nula deve ser maior que 1,812 ou menor que $-1,812$.

\section{Resultados e Discussão}

\subsection{Erosividade $\boldsymbol{x}$ ENOS e Dipolo do Atlântico}

Observou-se que o modelo de regressão obtido por Barbosa et al. (2015) apresentou resultados de erosividade satisfatórios, o que leva a compreender que o mesmo pode ser utilizado para obter índices de erosividade em outros locais com características climáticas semelhantes. Esse tipo de metodologia vem firmando-se há bastante tempo, e um exemplo disso é o trabalho de Almeida et al. (2012), no qual os autores analisaram a semelhança do tipo climático para extrapolar o uso de equações de regressão, de uma localidade para outra, na determinação da erosividade das chuvas.

Na Fig. 3, observam-se os valores correspondentes aos índices de erosividade anuais e as ocorrências dos
Tabela 4 - Classificação dos coeficientes de correlação de Pearson $(R)$ e de determinação $\left(R^{2}\right)$.

\begin{tabular}{lcc}
\hline$R$ & $R^{2}$ & Classificação \\
\hline 0 & 0 & Nula \\
$0,00-0,30$ & $0,00-0,09$ & Fraca \\
$0,30-0,60$ & $0,09-0,36$ & Média \\
$0,60-0,90$ & $0,36-0,81$ & Forte \\
$0,90-0,99$ & $0,81-0,99$ & Fortíssima \\
1 & 1 & Perfeita \\
\hline
\end{tabular}

Fonte: Cavalcante (2003).

fenômenos climáticos. A média anual foi de 14.646 MJ mm $\mathrm{ha}^{-1} \mathrm{~h}^{-1}$ ano $^{-1}$, no qual o ano de 1986 manteve-se acima dessa média (ano de Dipolo Negativo), quando no ano de 1987 ocorreu uma redução, possivelmente pela ocorrência do primeiro El Niño forte da série. Em 1988 e 1989, foram registradas as mais duradouras anomalias de Dipolo Negativo, coincidindo com os anos de La Niña mais intensos, o que resultou justamente em anos com potencial erosivo acima da média.

O ano de 1990 foi um ano neutro de anomalias, quando comparados aos outros anos, foi o que obteve os menores valores de ION e GIH. No ano de 1991, ocorreu um El Niño fraco juntamente com um curto período de Dipolo Negativo, o que não levou a nenhuma variação significativa na erosividade. Em 1992, mesmo com a erosividade anual acima da média devido ao período chuvoso da região (janeiro a abril), houve a ocorrência de um El Niño forte juntamente com Dipolo positivo, o que culminou na predominância da classe "Baixa Erosividade" (Tabela 2), neste ano. D'odorico et al. (2001) realizaram um estudo semelhante no sudoeste dos Estados Unidos. Os autores chegaram a resultados similares, ou seja, com a influência

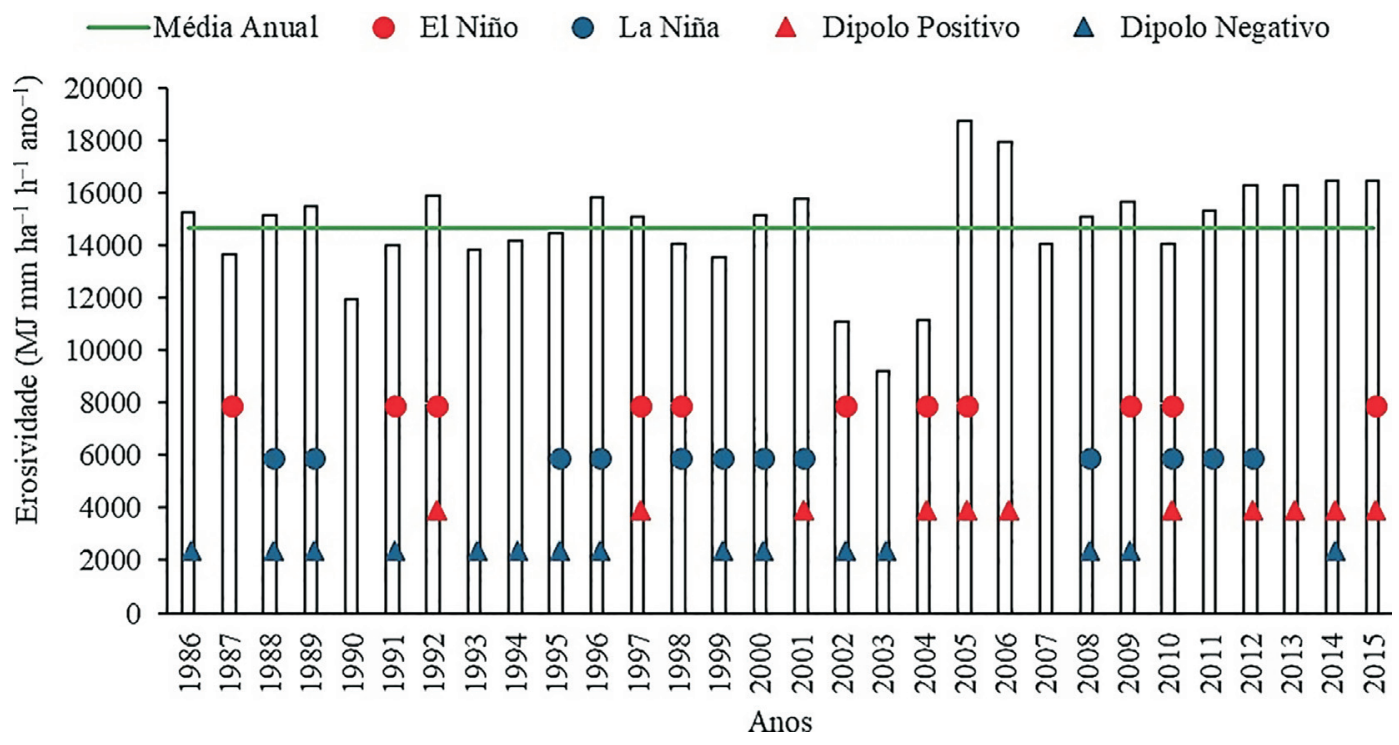

Figura 3 - Totais anuais de erosividade e ocorrência das anomalias no período de 1986 a 2015. 
de um forte El Niño em conjunto com o Dipolo Positivo, ocorreu uma perceptível variação no fator erosivo, mostrando a existência de uma previsibilidade potencial (de curto prazo) dos anos anormalmente erosivos. Vale salientar que a hipótese de linearidade entre a erosividade e os fenômenos sugere uma compreensão mais profunda dos vínculos entre o solo e a dinâmica climática.

De 1994 a 1996, anos de Dipolo Negativo, houve um aumento do total anual erosivo, ocorrendo uma redução em 1997 e 1998 (provavelmente devido ao forte El Niño), voltando a aumentar em 1999, 2000 e 2001, quando ocorreu Dipolo Negativo e também um La Niña forte. Ainda em 2001, iniciou-se um Dipolo Positivo que coincidiu com um evento de El Niño em 2002, no qual se observa uma diminuição brusca nos potenciais erosivos (mesmo sobre período de Dipolo Negativo em 2002 e 2003).

Ao contrário das baixas erosividades que se esperavam para 2004 e 2005, onde ocorreram Dipolos Positivos e El Niño, ambos tiveram um aumento na erosividade. Possivelmente em Belém as influências dos fenômenos não permanecem por muito tempo por sofrerem interferências de rios que contribuem para as atividades convectivas constantes (Moura e Vitorino, 2012). Essa "inconstância climática", quando comparada ao resto da região amazônica, pode ser percebida em 2005, quando na Amazônia ocorreu uma das maiores secas de todos os tempos (Zeng et al., 2008). Segundo Tavares e Mota (2012), durante esse mesmo ano, em Belém, ocorreu a maior chuva registrada nos últimos 110 anos $(200,4 \mathrm{~mm})$ e foi, justamente, o mesmo ano para o qual se obteve o maior total anual de erosividade.

Essa variabilidade climática e pluviométrica também pode ser explicada, do ponto de vista meteorológico, pela variedade de componentes atmosféricos que causam precipitação na região. Mehl et al. (2001) chegaram à conclusão que em anos sobre a influência de fenômenos climáticos, o sinal convectivo sobrepõe-se aos sistemas atmosféricos existentes em diversas regiões do Brasil. Já Paula et al. (2010) afirmam que mesmo em anos com ocorrência de fenômenos, a ação dos sistemas formadores de chuva faz com que os mecanismos climáticos atuem normalmente, porém, sob ação de outros fatores externos, que geralmente são locais de baixa altitude, o que causa essa grande variação.

Em 2006 (ano de Dipolo Positivo) e 2007 (La Niña) houve uma diminuição na erosividade, voltando a ficar acima da média em 2008, onde ocorreu um La Niña juntamente com um Dipolo Negativo. A seca de 2010 apresentou maior abrangência que a de 2005 e, nesse mesmo ano, ocorreram El Niño e Dipolo Positivo, fazendo a erosividade anual ter uma queda e ficar abaixo da média. Esses resultados acordam com os de Mello et al. (2012), que realizaram um estudo no sul de Minas Gerais, concluindo que de 2006 a 2010 houve uma grande representatividade na correlação entre os valores de TSM no pacífico (principalmente os positivos) e as chuvas erosivas.

A erosividade começou a aumentar novamente em 2011, possivelmente devido à influência do La Niña. Os anos 2009, 2012 e 2014 foram marcados por chuvas excepcionais em toda a região amazônica. Durante esses anos em Belém, constatou-se erosividades anuais acima da média, ocorrendo Dipolos Negativos em 2009, 2014; e La Niña em 2012. Em 2013 a erosividade manteve-se acima da média, pois o período de Dipolo Positivo foi bem curto, não causando tanta influência. $\mathrm{O}$ ano de 2015 foi semelhante a 2005, no qual mesmo ocorrendo um dos El Niño mais forte e com ocorrência de Dipolo Positivo, a erosividade total anual foi acima da média e uma das maiores calculadas.

O resumo estatístico apresentado na Fig. 4 deve-se ao fato de que apenas o valor médio não é suficiente para

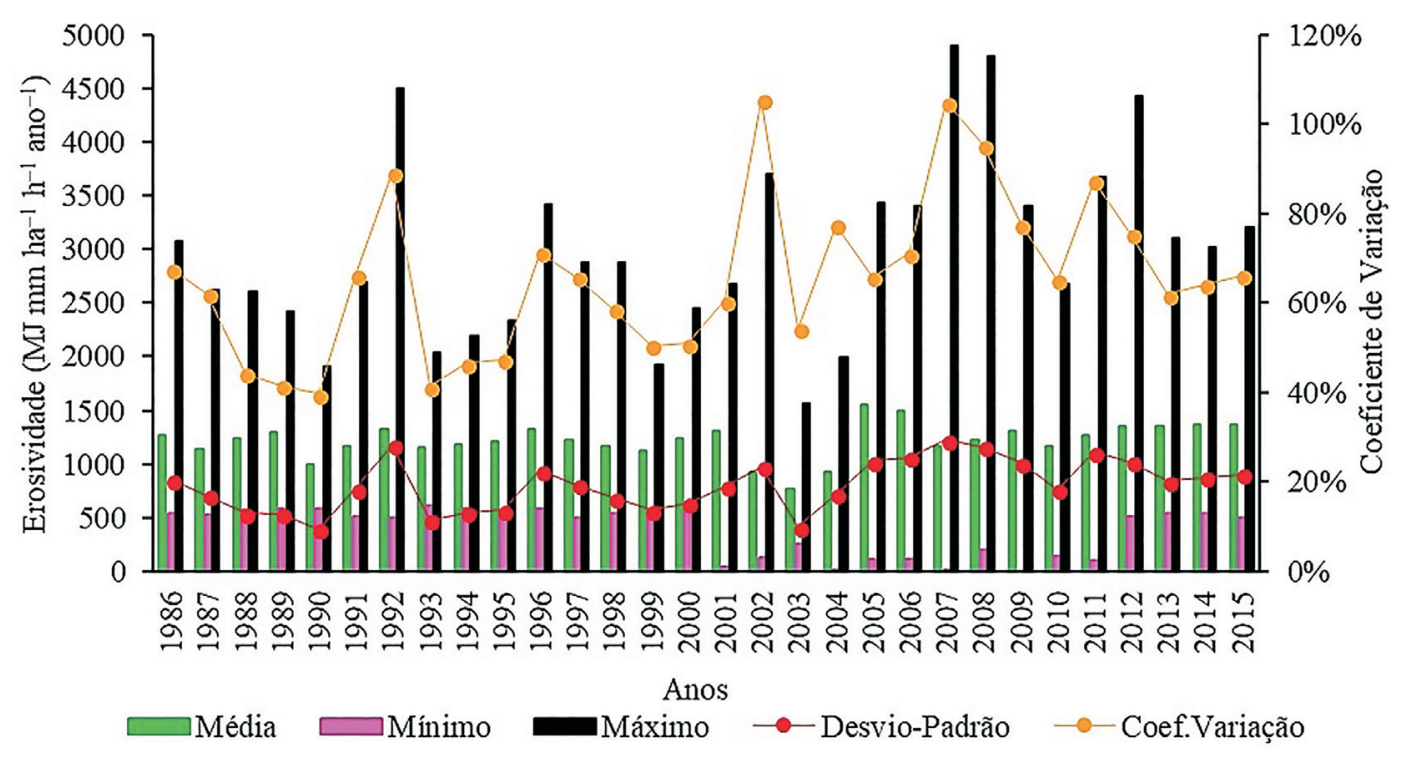

Figura 4 - Resumo estatístico dos índices de erosividade anuais. 
indicar como os dados realmente se comportaram. Os coeficientes de variação mensais dentre todos os anos ficaram em torno dos 60\%. O ano com menor variabilidade entre os dados foi o de 1990, que apresentou um coeficiente de variação de $39,67 \%$ e ao mesmo tempo o menor desviopadrão que foi de $395,04 \mathrm{MJ} \mathrm{mm} \mathrm{ha}^{-1} \mathrm{~h}^{-1}$ ano $^{-1}$, também demonstrando uma menor dispersão estatística. Este fato pode ser atribuído justamente por ter sido um ano Neutro de fenômenos climáticos.

Em 1993 obteve-se o segundo menor valor do coeficiente de variação $(41,43 \%)$, coincidentemente este ano também foi Neutro de eventos ENOS. O coeficiente de variação voltou a aumentar no ano de 1996 (71,40\%), que passava por um período de Dipolo negativo em conjunto com um La Niña Moderado. No ano de 2004 encontra-se o menor valor mínimo (15,56 MJ mm ha $\left.\mathrm{h}^{-1} \mathrm{mês}^{-1}\right)$, neste ano houve a ocorrência de um El Niño em paralelo a um Dipolo Positivo.

Em praticamente todo o ano de 2008, houve a ocorrência de um La Niña Moderado em conjunto com um Dipolo Negativo, onde neste mesmo ano obteve-se o segundo maio valor de coeficiente de variação $(95,37 \%)$ e o segundo maior valor máximo (4.793,68 $\mathrm{MJ} \mathrm{mm} \mathrm{ha}^{-1} \mathrm{~h}^{-1}$ mês $\left.{ }^{-1}\right)$. O ano de 2002 foi quando se obteve o maior coeficiente de variação $(105,46 \%)$, representando que os valores nesses anos foram os mais heterogêneos e de maior variabilidade, porém foi no ano de 2007 que se encontrou o maior valor de desvio-padrão, o qual foi de 1.230,06 MJ $\mathrm{mm} \mathrm{ha} \mathrm{h}^{-1} \mathrm{ano}^{-1}$, ou seja, nesse ano a variação dos dados de erosividade em relação à média foi bem maior do que em relação aos outros.

Observou-se que os anos em que os eventos se apresentaram nas classes "Moderado" ou "Forte" foram os que, de certo modo, influenciaram no potencial erosivo da chuva. Um exemplo disto foi o ano de 2007, quando a maior erosividade mensal foi encontrada, também se obteve o maior desvio-padrão e o segundo maior coeficiente de variação (105,08\%). Foi justamente no mesmo ano em que houve um evento La Niña Moderado. Já o ano de 2002, quando ocorreu o maior coeficiente de variação e a menor quantidade de meses classificados como de "Alta Erosividade", foi um ano de ocorrência de El Niño Moderado.

\subsection{Erosividade $x$ ION}

Na Fig. 5 é possível notar que 20 anos apresentaram correlação negativa $(-0,80$ a $-0,09)$ e 10 anos correlação positiva $(0,06$ a 0,77$)$. Somando os anos com nível médio e forte, tem-se 24 anos de correlação aceitável, ou seja, uma boa representatividade. Vale destacar que dos nove anos que ocorreram eventos ENOS com intensidade forte, sete apresentaram-se justamente em um nível de correlação forte (1988, 1989, 1992, 1997, 1998, 2000 e 2015), sendo que na maioria desses anos a correlação foi negativa, ou seja, enquanto um evento ENOS quente/frio ocorria, a erosividade diminuía/aumentava.

$\mathrm{Na}$ análise do coeficiente de determinação, 13 anos apresentaram valores acima do aceitável $(0,36)$, como se pode observar na Fig. 6, sendo que em sete anos ocorreram eventos ENOS com intensidade forte (1988, 1989, 1992, 1997, 1998, 2000 e 2015). Pode-se compreender que em anos que ocorrem fenômenos de maiores intensidades, a erosividade da chuva sofre maior influência. Percebe-se então, com esses dados, que a intensidade do evento se mostra um fator importante para a análise de qualquer estudo que venha relacionar variáveis climáticas com outros fatores. Esse fato é reiterado pelo trabalho de Romero et al. (2007), que apresentou uma pesquisa realizada na região nordeste do Peru, em que os valores de erosividade da chuva sofreram mudanças principalmente durante intensos eventos de ENOS (1992, 1997 e 1998).

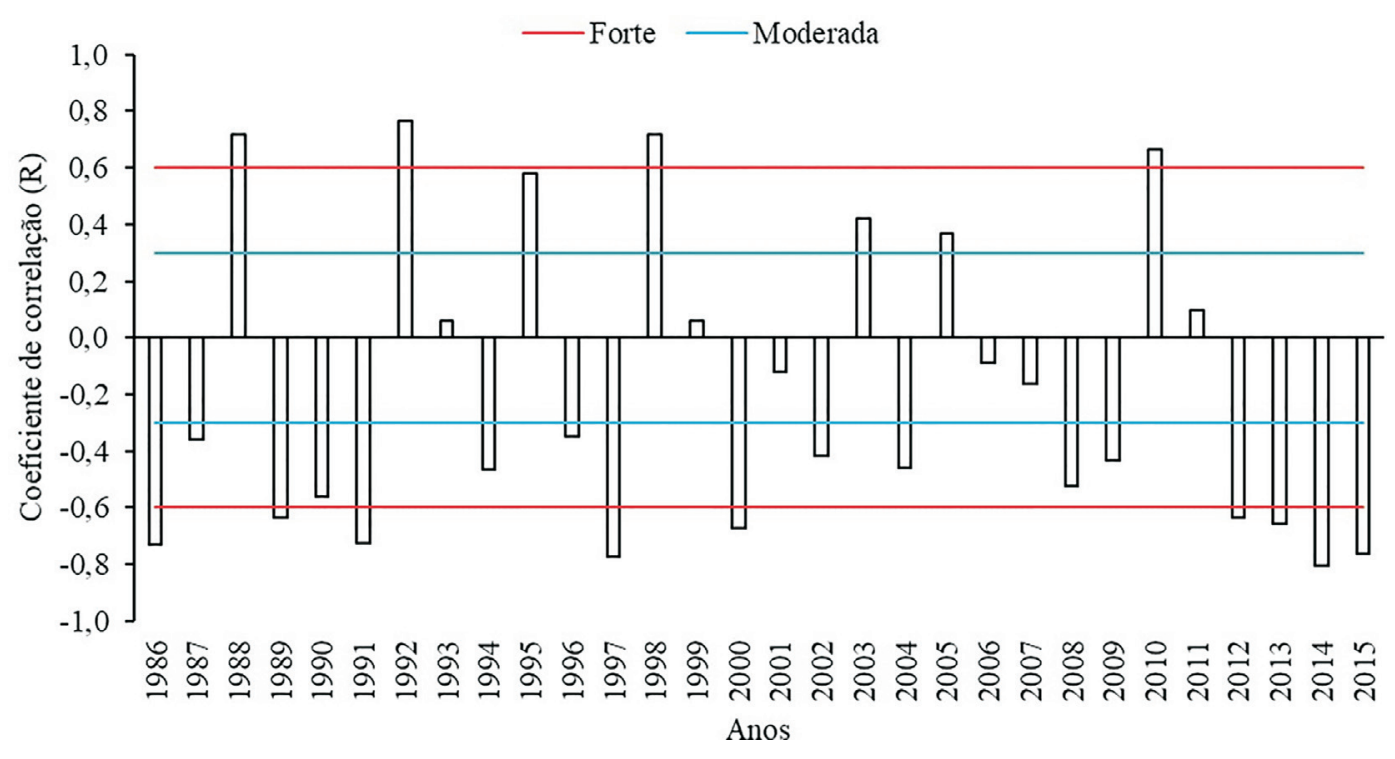

Figura 5 - Coeficiente de correlação entre $E I_{30}$ e ION. 


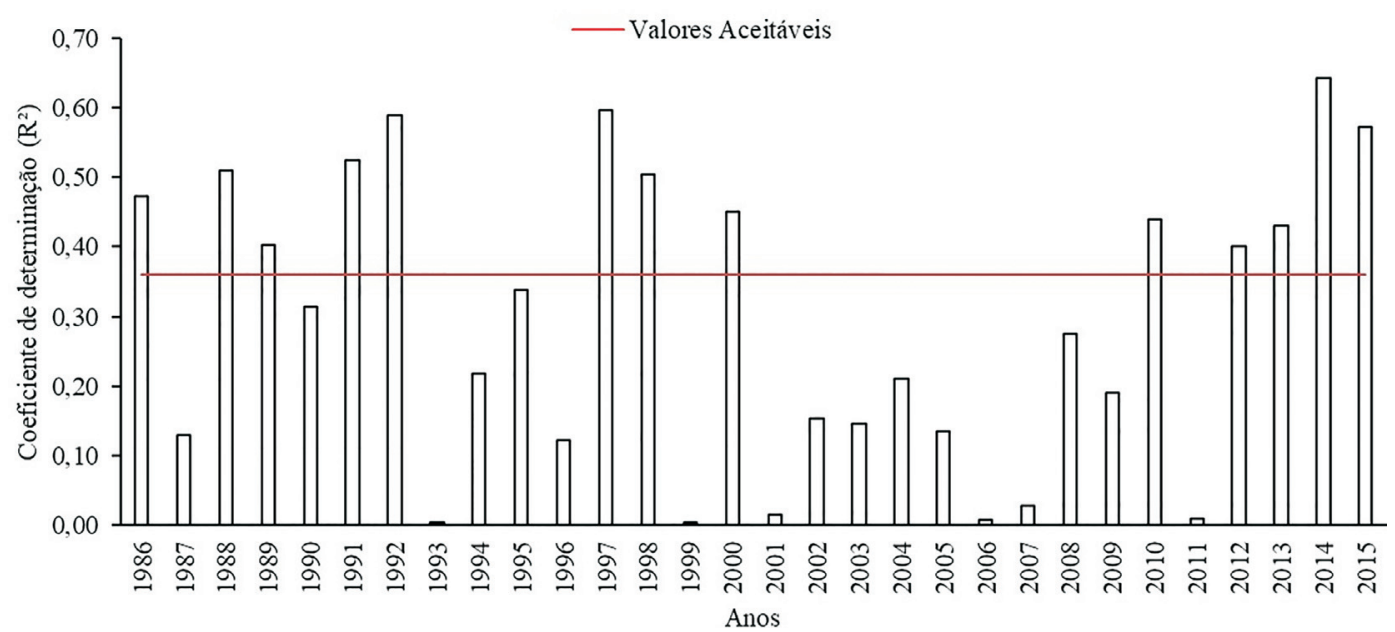

Figura 6 - Coeficiente de determinação entre $E I_{30}$ e ION.

Na Fig. 7 observa-se que 5 valores calculados de $t$ foram superiores e 10 inferiores ao valor crítico $(1,812 \mathrm{e}$ -1,812), ou seja, para estes 15 anos deve-se rejeitar a hipótese nula e concluir que existem evidências suficientes para afirmar que os valores de $R$ obtidos foram significantes. Isso equivale à metade da série, e novamente na maioria desses anos ocorreram eventos de ENOS fortes.

\subsection{Erosividade $x$ GIH}

Na Fig. 8, percebe-se que 26 anos apresentaram correlação negativa $(-0,07$ a $-0,91)$ e apenas quatro anos correlação positiva $(0,06$ a 0,31$)$. Somando os anos com nível médio e forte, tem-se 17 anos de correlação aceitável, ou

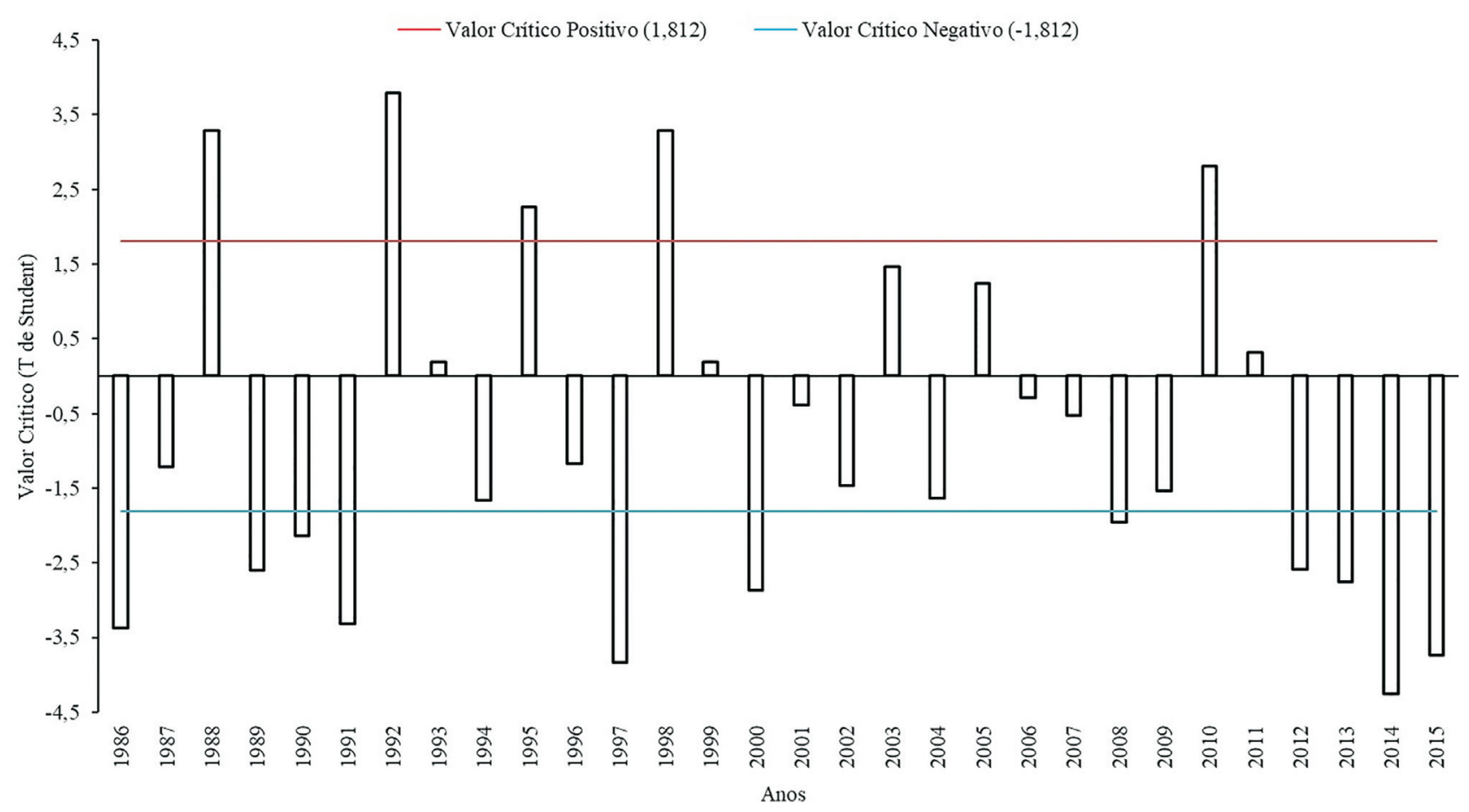

seja, mais que a metade da série. Em todos os anos de correlação forte ocorreram fenômenos de Dipolo do Atlântico, sendo em sua maioria negativos. É possível interpretar que, de maneira generalizada, a fase negativa do Dipolo Atlântico possui maior influência sobre a erosividade, sendo que na maioria desses anos o potencial erosivo apresentou-se elevado.

Na Fig. 9 podem-se observar os resultados obtidos através de regressão linear, em que dez anos apresentaram valores acima do aceitável $(0,36)$.

Dentre os eventos que obtiveram correlação forte, apenas em 2014 não houve eventos ENOS. Os anos de 1989 e 2000 foram anos de ocorrência tanto de La Niña forte

Figura 7 - Teste T de Student para correlação entre $E I_{30}$ e ION. 


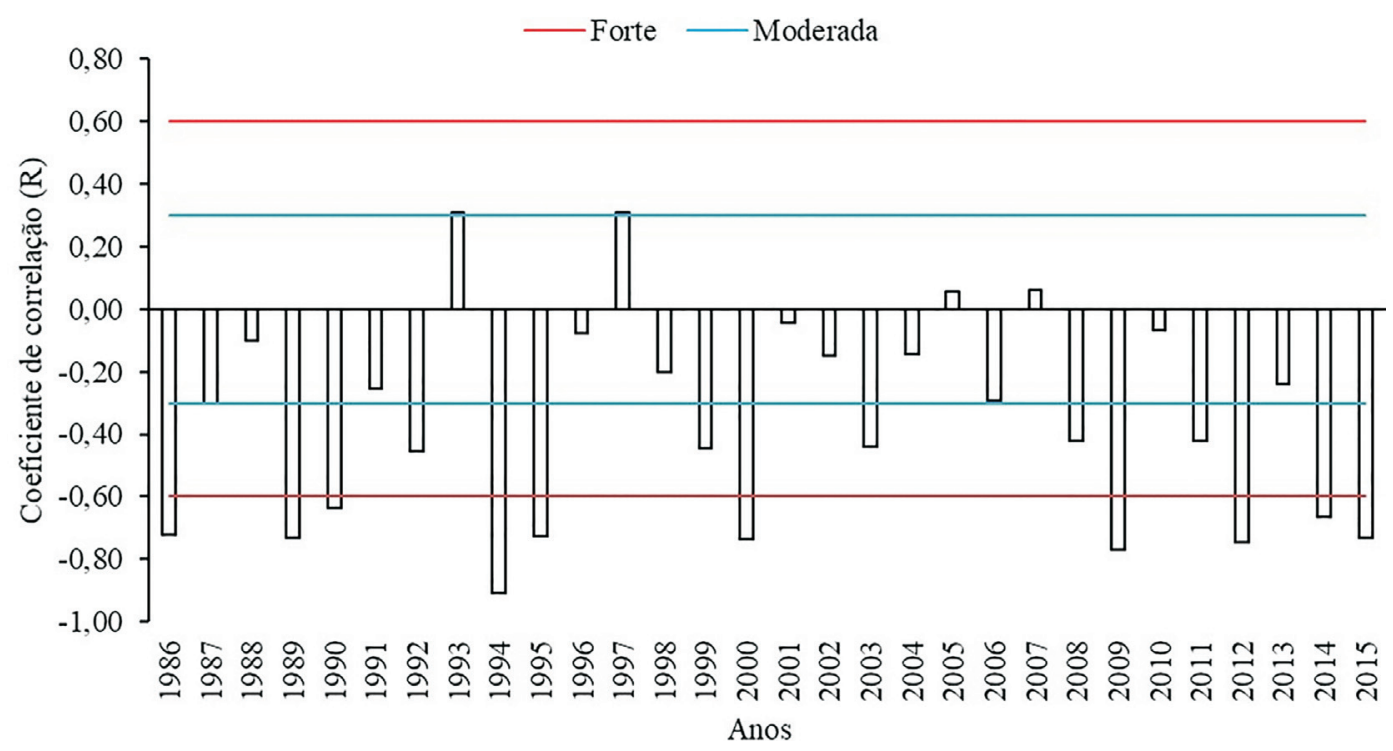

Figura 8 - Coeficiente de correlação entre $E I_{30}$ e GIH.

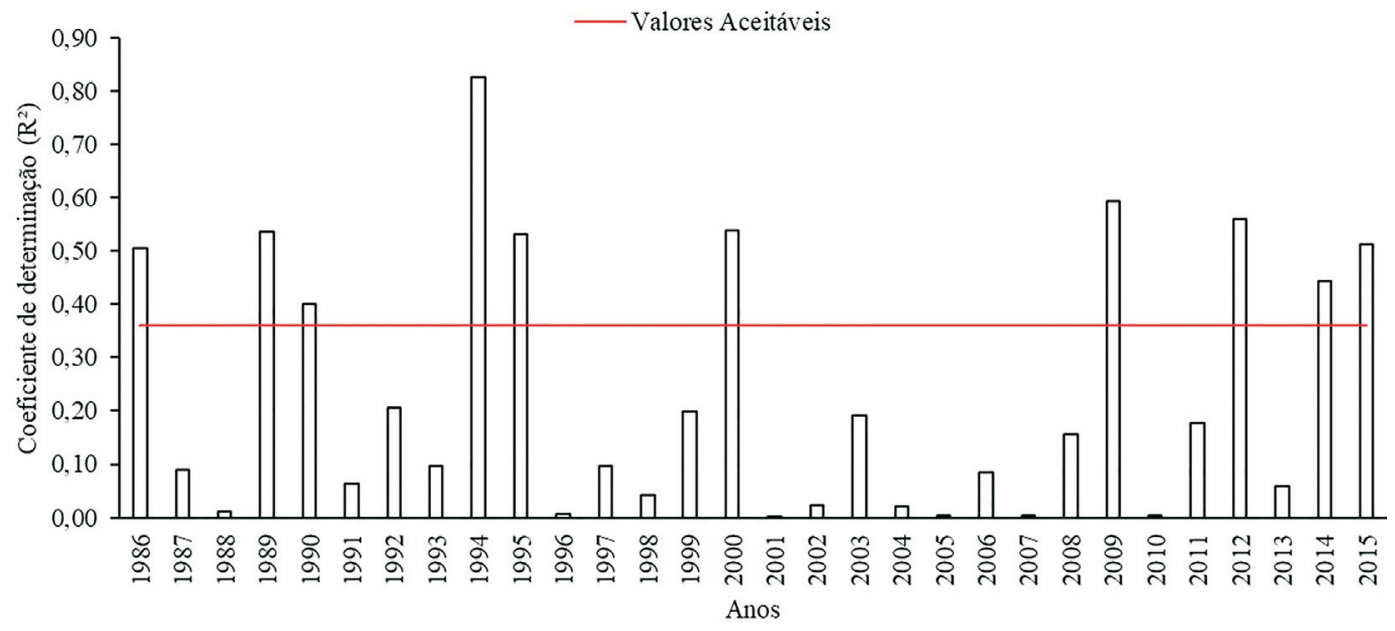

Figura 9 - Coeficiente de determinação entre $E I_{30}$ e GIH.

quanto de Dipolo Negativo, o que pode demonstrar novamente a influência de uma anomalia sobre a outra, intensificando seus efeitos sobre a erosividade. Nos demais anos ocorreram eventos de El Niño fracos e moderados, sendo que o único evento forte foi evidenciado apenas em 2015.

De acordo com a Agência Nacional das Águas (2012), as duas maiores enchentes na Amazônia ocorreram em 2009 e 2012. Nesses dois anos ocorreram, em meses pontuais, divergências. Em 2009, março e maio apresentaram erosividades altíssimas, já 2012 apenas março (possivelmente devido ao efeito do Dipolo Negativo). Enquanto isso, o segundo semestre de 2009 apresentou um déficit de erosividade devido ao El Niño desse ano. Segundo Brito e Silva (2012), os efeitos do Dipolo Negativo também foram perceptíveis na Região Nordeste do Brasil, o que confirma a atuação do fenômeno neste período. Os autores afirmam que os dois principais eventos pluviométricos para o muni- cípio de Crato (CE) foram os que ocorreram em janeiro de 2011 e em março de 2012, causando alagamentos pela cidade.

Pode-se observar na Fig. 10 que nenhum valor obtido de $t$ foi superior ao valor crítico. Porém, 10 foram inferiores ao valor crítico negativo, o que nos leva a afirmar novamente que nesses anos os valores de $R$ obtidos foram significantes. Mesmo não tendo uma boa representatividade, deve-se ter em mente que a correlação está sendo realizada entre duas variáveis que não tem uma relação direta.

De maneira geral, obtiveram-se bons resultados de correlações, principalmente com os eventos ENOS. Isso pode significar uma possível previsibilidade de eventos extremos de chuva, a partir dos índices climáticos. Os dados desse estudo também incentivam a realização de pesquisas semelhantes, já que a mais recente no Brasil é de Paula et al. (2010). Por exemplo, Chen e Zah (2018) reali- 


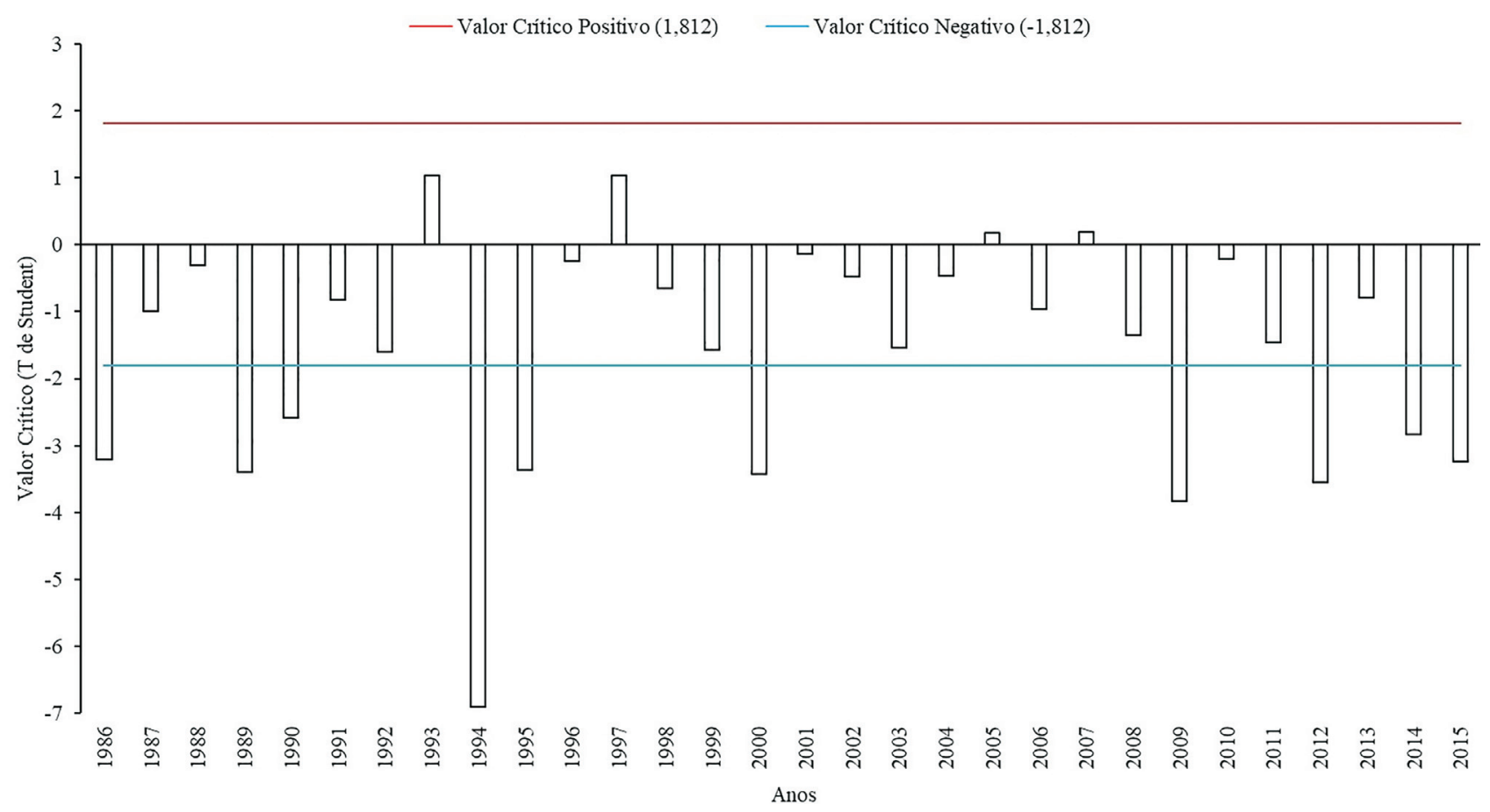

Figura 10 - Teste T de Student para correlação entre $E I_{30}$ e ION.

zaram uma análise semelhante para província de Fujian (China) e concluíram que a erosividade das chuvas tem uma correlação particularmente forte com o ENOS. A influência do fenômeno sobre erosividade foi demonstrada por uma correlação significativa ( $95 \%$ de nível de confiança). Os autores afirmaram ainda que o índice de erosividade aumentou à medida que o índice climático aumentava. Porém, deve-se levar em consideração a particularidade de cada região e outros padrões espaciais/temporais, que afetam o tempo e o clima na região de estudo, já que para Santos (2008), nas regiões Norte e Nordeste a variação no regime de chuvas é consequência da atuação também de diversos mecanismos meteorológicos, como as Perturbações Ondulatórias nos Alísios (Linhas de Instabilidade), Vórtices Ciclônicos de Alto Nível e Sistemas Frontais.

\section{Conclusão}

Percebe-se que a variabilidade do potencial erosivo tem, sim, relação com os fenômenos estudados. O El Niño, juntamente com Dipolo Positivo, tende a reduzir a erosividade, enquanto o La Niña, em conjunto com Dipolo Negativo, implica na intensificação e aumento da mesma. Observaram-se os menores potenciais erosivos em anos de El Niño intenso, obtendo-se coeficientes de correlação e determinação fortes. Coincidência de La Niña intenso e Dipolo Negativo representam maiores coeficientes de correlação e determinação, significando o aumento da erosividade. Houve fraca correlação do potencial erosivo durante Dipolo Positivo. Assim, destaca-se que os efeitos dos fenômenos sobre o potencial erosivo das chuvas não so- mente se repetiram como também mostraram fortes correlações com os índices climáticos (principalmente do ENOS) mesmo diante da instabilidade climática da região analisada. De maneira geral, outros fatores, importantes nas áreas de engenharia e meio ambiente, estão sendo afetados pelos fenômenos climáticos e precisam ser analisados, considerando-se as mudanças climáticas. Os dados deste estudo podem fornecer uma base teórica para o tratamento abrangente e prevenção a eventos extremos, e tem importância significativa para o monitoramento, avaliação, previsão e tratamento da erosão do solo.

\section{Agradecimentos}

Os autores agradecem ao Prof. Teodorico Alves Sobrinho da UFMS o incentivo para realização do trabalho. Os autores agradecem ao INMET pelos dados de precipitação disponibilizados. O primeiro autor agradece uma bolsa de mestrado financiada pela CAPES e o segundo autor agradece a bolsa de produtividade em pesquisa financiada pelo CNPq (processo n. 304936/2015-4).

\section{Referências}

ALMEIDA, C.O.S.; AMORIM, R.S.S.; ELTZ, F.L.F.; COUTO, E.G.; JORDANI, S.A. Erosividade da chuva em municípios do Mato Grosso: distribuição sazonal e correlações com dados pluviométricos. Revista Brasileira de Engenharia Agrícola e Ambiental, v. 16, n. 2, p. 142-152, 2012.

ALVARES, C.A; STAPE, J.L; SENTELHAS, P.C; GONÇALVES, J.L.M; SPAROVEK, G. Köppen's climate classification map for Brazil. Meteorologische Zeitschrift, v. 22, n. 6, p. 711-728, 2013. 
ANA. Agência Nacional das Águas. Disponível em http://www2.ana.gov.br/Paginas/imprensa/noticia.aspx?Lis $\mathrm{t}=\mathrm{ccb} 75 \mathrm{a} 86-\mathrm{bd} 5 \mathrm{a}-4853-8 \mathrm{c} 76-\mathrm{cc} 46 \mathrm{~b} 7 \mathrm{dc} 89 \mathrm{a} 1 \& \mathrm{ID}=10536$. Acesso em: 20 set. de 2017.

BARBOSA, A.J.S.; BLANCO, C.J.C.; MELO, A.M.Q. Determinação do Fator Energético da chuva $(\mathrm{R})$ para Belém-PA. In: CONGRESSO INTERNACIONAL DE HIDROSSEDIMENTOLOGIA, 1., Porto Alegre. Anais... Porto Alegre: UFRGS, 2015.

BASTOS, T.X.; PACHECO, N.A.; NECHET, D.; SÁ, T.D.A. Aspectos climáticos de Belém nos últimos cem anos. Belém: Embrapa Amazônia Oriental, 2002. 31p. (Embrapa Amazônia Oriental. Documentos, 128).

BATJES, N.H. Global Assessment of Land Vulnerability to Water Erosion on a by grid. Land Degradation \& Development, v. 7, n. 4, p. 353-365, 1996.

BRITO, D.S.; SILVA, J.M.O. Estudo dos Impactos Pluviométricos e os Eventos Extremos no Município de Crato - CE. Revista Geonorte, v. 3, n. 8, p. 964-976, 2012.

CAVALCANTE, J.C. Mortalidade em menores de um ano: utilização de novos indicadores para avaliação. Dissertação de mestrado em Saúde da criança, Centro de Ciências da Saúde. Departamento de Tocoginecologia. Universidade Federal de Alagoas. 2003.

CHEN, S.; ZHA, X. Effects of the ENSO on rainfall erosivity in the Fujian Province of southeast China. Science of The Total Environment, v. 621, p. 1378-1388, 2018.

CHEN, Z.; WEN, Z.; WU, R.; LIN, X.; WANG, J. Relative importance of tropical SST anomalies in maintaining the Western North Pacific anomalous anticyclone during El Niño to La Niña transition years. Climate Dynamics, v. 46, n. 3-4, p. 1027-1041, 2016.

COLLINS, M.; AN, S.; CAI, W.; GANACHAUD, A.; GUILYARDI, E. et al. The impact of global warming on the tropical Pacific Ocean and El Niño. Nature Geoscience, vol. 3, p. 391-397, 2010.

D'ODORICO, P.; YOO, J.C.; OVER, T.M. An assessment of ENSO-induced patterns of rainfall erosivity in the southwestern United States. Journal of Climate, v. 14, n. 21, p. 4230-4242, 2001.

EVANGELISTA, A.W.P; VIEIRA, M.A.; SILVA, M.C.; SOUZA, J.L.M. Erosividade e características hidrológicas das chuvas de Viçosa (MG). IRRIGA, v. 17, n. 4, p. 456-468, 2012.

FEBLES, J.M.; TOLÓN, A.; VEGA, M.B. Edaphic indicators for assesment of soil erosion in karst regions, province of Havana, Cuba. Land degradation \& development, v. 20, n. 5, p. 522-534, 2009.

FERREIRA, A.G.; MELLO, N.G.S. Principais Sistemas Atmosféricos Atuantes sobre a Região Nordeste do Brasil e a Influência dos Oceanos Pacífico e Atlântico no Clima da Região. Revista Brasileira de Climatologia, v. 1, n. 1, p. 15-26, 2005.

GOLDEN GATE WEATHER SERVICES. ENSO Years based on Oceanic Niño Index (ONI). On line. Disponível na Internet: http://ggweather.com/enso/oni.htm. Acesso em: 15 ago. de 2016.

IBGE. Instituto Brasileiro de Geografia e Estatística. Disponível em: https://cidades.ibge.gov.br/. Acesso em ago. de 2016.
IRVEM A.; TOPALOGLU F.; UYGUR, V. Estimating spatial distribution of soil loss over Seyhan river basin in Turkey. Journal of Hydrology. v. 336, n. 2, p. 30-37, 2007.

LEE, J.; HEO, J. Evaluation of estimation methods for rainfall erosivity based on annual precipitation in Korea. Journal of Hidrology, v. 409, n. 1-2, p. 30-48, 2011.

MACHADO, R.L.; CARVALHO, D.F.; ROUWS, J.R.C.; GOMES, D.P.; EDUARDO, E.N. Erosividade das chuvas associada a períodos de retorno e probabilidade de ocorrência no estado do Rio de Janeiro. Revista Brasileira de Ciência do Solo, v. 37, n. 2, p. 529-547, 2013.

MARCUZZO, F.; OLIVEIRA, N.L.; CARDOSO, M.R.D. Tendência do Número de Dias de Chuva no Estado do Mato Grosso do Sul e Sua Relação com o Fenômeno ENOS. Revista Brasileira de Geografia Física, v. 5, n. 5, p. 11331144,2012

MEHL, H.U.; ELTZ, F.L.F.; REICHERT, J.M.; DIDONÉ, I.A. Caracterização de padrões de chuvas ocorrentes em Santa Maria (RS). Revista Brasileira de Ciência do Solo, v. 25, n. 2, p. 475-483, 2001.

MELO, A.M.Q.; BLANCO, C.J.C.; BARBOSA, A.J.S.; SILVA, F.S. Digitalização de pluviogramas para fins de determinação do fator energético da chuva (r) para a cidade de Belém-PA. In: ENCONTRO NACIONAL DE ENGENHARIA DE SEDIMENTOS, 11., João Pessoa. Anais... Bento Gonçalves: ABRH, 2014.

MELLO, C.R.; NORTON, L.D.; CURI, N.; YANAGI, S.N.M. Sea surface temperature (SST) and rainfall erosivity in the Upper Grande River Basin, Southeast Brazil. Ciência e Agrotecnologia, v. 36, n. 1, p. 53-59, 2012.

MENEZES, H.E.A.; BRITO, J.I.B.; SANTOS, C.A.C.; SILVA, L.L. A relação entre a temperatura da superfície dos oceanos tropicais e a duração dos veranicos no estado da Paraíba. Revista Brasileira de Meteorologia, v. 23, n. 2, p. 152-161, 2008.

MOURA, M.N.; VITORINO, M.I. Variabilidade da precipitação em tempo e espaço associada à Zona de Convergência Intertropical Variability of rainfall in time and space associated with Intertropical Convergence Zone. Revista Brasileira de Meteorologia, v. 27, n. 4, p. 475-483, 2012.

NOAA. Cold and warm episodes by season. Disponível em: http://www.cpc.ncep.noaa.gov/products/analysis monitoring/ensostuff/ensoyears.shtml. Acesso em: 08 ago. de 2016.

NÓBREGA, R.S.; SANTIAGO, G.A.C.F.; SOARES, D.B. Tendência do Controle climático oceânico sob a variabilidade Temporal da Precipitação no Nordeste do Brasil. Revista Brasileira de Climatologia, v. 18, p. 276-292, 2016.

NUR'UTAMI, M.N.; HIDAYAT, R. Influences of IOD and ENSO to Indonesian rainfall variability: role of atmosphere-ocean interaction in the Indo-Pacific sector. Procedia Environmental Sciences, v. 33, p. 196-203, 2016.

OKUMURA, Y.; XIE, S.; NUMAGUTI, A.; TANIMOTO, Y. Tropical Atlantic air-sea interaction and its influence on the NAO. Geophysical Research Letters, v. 28, n. 8, p. 15071510,2001

PAULA, G.M.; STRECK, N.A.; ZANON, A.J.; ELTZ, F.L.F.; HELDWEIN, A.B. et al. Influência do fenômeno El Niño na erosividade das chuvas na região de Santa Maria (RS). Revista Brasileira de Ciência do Solo, v. 34, n. 4, p. 13151323, 2010. 
REBOITA, M.S.; SANTOS, I.A. Influência de alguns padrões de teleconexão na precipitação no norte e nordeste do Brasil. Revista Brasileira de Climatologia, v. 15, n. 2, p. 28-48, 2015.

ROMERO, C.C.; BAIGORRIA, G.A.; STROOSNIJDER, L. Changes of erosive rainfall for El Niño and La Niña years in the northern Andean highlands of Peru. Climatic Change, v. 85, n. 3, p. 343-356, 2007.

SALES, A.B. Climatologia de dias de Tempestades nas Principais Cidades da Região Equatorial Brasileira e Projeções para o Futuro. 2014. 194 f. Tese (Doutorado) - Curso de Pós-graduação em Geofísica Espacial, Instituto Nacional de Pesquisas Espaciais, São José dos Campos, 2014.

SANTOS, E.V. dos. Estudo qualitativo das previsões de tempo publicadas nos jornais folha de São Paulo e Gazeta de Alagoas para Maceió. 2008. 83 f. TCC (Graduação) Curso de Meteorologia, Universidade Federal de Alagoas, Maceió, 2008.

SANTOS, G.G.; GRIEBELER, N.P.; OLIVEIRA, L.F.C. Intense rainfalls related to water erosion. Revista Brasileira de Engenharia Agrícola e Ambiental, v. 14, n. 2, p. 115-123, 2010 .
SOUZA, E.B.; KAYANO, M.T.; AMBRIZZI, T. Intraseasonal and submonthly variability over the eastern Amazon and Northeast Brazil during the autumn rainy season. Theoretical and Applied Climatology, v. 81, n. 3-4, p. 177-191. 2005.

TAVARES, J.P.N.; MOTA, M.A.S. Condições termodinâmicas de eventos de precipitação extrema em Belém-PA durante a estação chuvosa. Revista Brasileira de Meteorologia, v. 27, n. 2, p. 207-218, 2012.

WALTRICK, P.C.; MACHADO, M.A.M.; DIECKOW, J.; OLIVEIRA, D. Estimativas da erosividade de chuvas no estado do Paraná pelo método da pluviometria: Atualização com dados de 1986 a 2008. Revista Brasileira de Ciência do Solo, Viçosa, v. 39, n. 1, p. 256-267, 2015.

WISCHMEIER, W.H; SMITH, D.D. Predicting Rainfall-Erosion Losses from Cropland East of the Rocky Mountain. Agricultural Handbook 282, p. 47, 1965.

ZENG, N.; YOON, J.; MARENGO, J.A.; SUBRAMANIAM, A.; NOBRE, C.A.; MARIOTTI, A.; NEELIN, J.D. Causes and Impacts of the 2005 Amazon Drought. Environmental Research Letters, v. 3, n. 1, p. 014002, 2008.

This is an Open Access article distributed under the terms of the Creative Commons Attribution Non-Commercial License which permits unrestricted non-commercial use, distribution, and reproduction in any medium provided the original work is properly cited. 